\title{
Análise do Consumo da Carne de Peixe em Campo Grande - MS
}

\section{Analysis of the Fish Meat Consumption in Campo Grande - MS}

\author{
Anderson Ribeiro de Almeidaa ; Carla Maiga Crivelli Batista ${ }^{\mathrm{a}}$; Celso Correa de Souza ${ }^{\mathrm{b}}$; Daniel Massen Frainer ${ }^{\mathrm{b}}$ \\ ${ }^{a}$ Centro Universitário Anhanguera de Campo Grande. MS, Brasil. \\ bUniversidade Anhanguera-Uniderp, Programa de Pós-Graduação Stricto Sensu em Produção e Gestão Agroindustrial. MS, Brasil. \\ *E-mail:
}

\begin{abstract}
Resumo
Esta pesquisa buscou levantar informações visando oferecer subsídios para o desenvolvimento de estratégias mercadológicas para o aumento do consumo de carne de peixe em Campo Grande - MS. Foi realizada uma pesquisa de campo de caráter exploratório descritiva, por meio da aplicação de um questionário estruturado aplicado a uma amostra aleatória de 404 indivíduos adultos. O questionário buscou identificar o perfil, os hábitos, as atitudes e as preferências, a percepção e o grau de importância, por parte do consumidor, em relação ao consumo de carne de peixe. Constatou-se que a carne de peixe é muito apreciada pelo campo-grandense, principalmente, pelas mulheres (59\%). A faixa etária que mais aprecia a carne de peixe está situada entre 31 e 40 anos e renda familiar entre 2 a 4 salários-mínimos. A carne de peixe aparece em terceiro lugar no ranking das preferências. As espécies mais preferidas são pela ordem: pacú (piaractus mesopotamicus), pintado (pseudoplatystoma corruscans), dourado (salminus brasiliensis) e sardinha (Sardinella janeiro). Para aumentar o consumo de carne de peixe são necessárias ações de marketing, que informem aos consumidores sobre a importância nutricional dessa carne, bem como os benefícios que o seu consumo traz para a saúde e aumentar a oferta e a variedade do produto e baixar o seu preço.
\end{abstract}

Palavras-chave: Comportamento do Consumidor. Consumidor de Peixe. Estratégias Mercadológicas.

\begin{abstract}
This research sought to raise information aiming at offering subsidies for the marketing strategies development for increasing fish meat consumption in Campo Grande city, MS. A descriptive exploratory field survey was conducted through the application of a structured questionnaire applied to a random sample of 404 adult individuals from that city. The questionnaire sought to identify the profile, habits, attitudes and preferences, perception and degree of importance on the part of the consumer in relation to the fish meat consumption. It was observed that fish meat is highly appreciated in Campo Grande city, about 59\% are women who showed a higher preference for this type of meat, the age group that most appreciates fish meat is between 31 and 40 years old and family income between 2 and 4 minimum wages. The fish meat appears in third place in the ranking of preferences. The most preferred species are in the order: pacu (piaractus mesopotamicus), pintado (pseudoplatystoma corruscans), dourado (salminus brasiliensis) e sardinha (Sardinella janeiro). To increase the fish meat consumption in Campo Grande, marketing actions are necessary, as well as the benefits that its consumption brings to health. It is also necessary to increase the product supply and variety and lower its price.
\end{abstract}

Keywords: Consumer Behavior. Fish Consumer. Marketing Strategies.

\section{Introdução}

Hábitos alimentares saudáveis têm recebido maior atenção, sendo amplamente reconhecido que o consumo regular da carne de peixe é uma das possíveis práticas de melhoramento da saúde. Os peixes apresentam proteínas de elevado valor biológico, superando o leite e a carne bovina, e a sua gordura se destaca pela composição em ácidos graxos de importante valor nutricional para os seres humanos (PESCADOR, 2006).

A produção mundial de peixes comestíveis obteve um aumento de 5,8\% em 2014, comparado ao ano anterior, correspondente a 73,8 milhões de toneladas. O maior produtor de animais aquáticos do Mundo é a China, que sozinha produziu, em 2013, 43,5 milhões de toneladas, responsável por $61,70 \%$ do total da produção mundial, atingindo a um faturamento aproximado de U\$ 54,7 bilhões (Organización de las Naciones Unidas para la alimentación y la agricultura
[FAO], 2016).

O Brasil tem melhorado, significativamente, sua posição mundial nos últimos anos, saltando de décimo quinto produtor mundial, em 2009, para o décimo primeiro em 2012, contribuindo com 611,3 mil toneladas (sendo $1,40 \%$ do total da produção mundial) no mesmo período, correspondendo a uma receita aproximada de U\$ 806 milhões.

Com relação ao consumo mundial de pescado, esse aumentou, consideravelmente, nas últimas cinco décadas, passando de 9,9 kg/hab/ano, em 1960, para 18,8 kg/hab/ano em 2013. O consumo de peixes pela população brasileira é considerado baixo, quando comparado com países europeus ou latino-americanos, nos quais o consumo pode atingir o dobro do consumo no Brasil. No Brasil, em 2010, o consumo per capita aparente foi em média de 9,75kg/hab/ano (FAO, 2016; FAO, 2011).

A criação de peixes em Mato Grosso do Sul é considerada 
recente se comparada às outras atividades agropecuárias. Não existem informações atualizadas e sistematizadas da atividade à disposição da comunidade. Inclusive, os agentes institucionais e, em muitos casos, o Poder Público não dispõem de dados precisos sobre a produção, a comercialização e a distribuição do produto produzido no Estado. Embora a atividade de piscicultura tenha demonstrado sinais de crescimento no Estado, a participação relativa da sua produção em níveis nacionais é muito pequena, sendo de $3,03 \%$ da produção nacional, o que corresponde a $14.523,8$ toneladas anuais de peixes (BRASIL, 2012; RESENDE; TAKAGI; LOESCHNER, 2011).

Quanto ao consumo de peixes, no Estado de Mato Grosso do Sul, a quantidade consumida ainda é pequena, mas com tendência de aumentar, principalmente, com o aumento da produção e o consequente barateamento do produto ao consumidor final. Por outro lado, o consumidor brasileiro tem se tornado mais exigente quanto à decisão de adquirir carne de peixe no mercado varejista, motivado pela globalização, que propiciou a democratização da informação e acesso aos padrões exigidos pelos consumidores de outros países já consolidados no consumo de peixes (DA SILVA et al., 2016). Segundo Kotler e Keller (2012), os fatores que influenciam a decisão de compra do consumidor, no momento da aquisição dos produtos, são culturais, sociais, pessoais e psicológicos.

O marketing é uma ferramenta indispensável no momento de abrir um novo negócio, pois é através desse que se analisa e constata a viabilidade do negócio. Sua essência é baseada na troca, em que empresa e cliente são artífices de um mesmo sistema, que deve gerar satisfação mútua no sentido de manter uma boa relação entre cliente e fornecedor (ROCHA; FERREIRA; SILVA, 2013).

Neste contexto, esta pesquisa procurou identificar e descrever as características, percepções e exigências dos consumidores campo-grandenses com relação à carne de peixe, visando oferecer subsídios para o desenvolvimento de estratégias mercadológicas para o aumento do consumo de carne de peixe na cidade de Campo Grande - MS. Identificar, também, o segmento do mercado consumidor da carne de peixe na cidade de Campo Grande, através do perfil, hábitos e preferências do consumidor, com a finalidade de oferecer subsídios para o desenvolvimento da cadeia produtiva do peixe.

\section{Material e Métodos}

A pesquisa pode ser considerada como quali-quantitativa, desenvolvida junto aos consumidores residentes na cidade de Campo Grande - MS, por meio da aplicação de um questionário estruturado aplicado a uma amostra aleatória da população dessa cidade.

O questionário foi dividido em três partes: a primeira parte contemplava o perfil dos consumidores, envolvendo aspectos demográficos do consumidor; a segunda parte constava de questões relativas aos hábitos do consumidor de carne de peixe, contemplando as variáveis nível de preferência em relação às outras carnes, frequência de consumo, forma de preparo, espécies preferidas, locais de consumo fora de casa, locais de compra, cortes preferidos e, tipos de embalagens; a terceira parte constou de um bloco de nove questões em escala Likert de sete pontos, que tratava da percepção do consumidor sobre a importância de alguns fatores relativos à carne de peixe vendida em supermercados e peixarias da cidade, contemplando preço, sabor, cheiro, firmeza da carne, aparência, apresentação, espinhos e atendimento, cujas respostas foram dadas em sete níveis de importância, sendo: 1 = nada importante até $7=$ muito importante, com o nível intermediário $4=$ indiferente.

Foram calculadas as médias aritméticas, os desvios padrões e os coeficientes de variações com a finalidade de se determinar, para cada variável, o nível de importância das opiniões dos entrevistados e como era a distribuição dessas opiniões em torno desse parâmetro. Foi, também, possível calcular a média aritmética geral, uma vez que todas as questões foram respondidas sempre pelo mesmo número de entrevistados.

O dimensionamento da amostra foi feito de acordo com Fonseca e Martins (2006), considerando um nível de confiança de $95 \%$, erro amostral de 5\%, uma proporção de consumidores de carne de peixe de $50 \%$ (pior caso e maior amostra), e população infinita. O tamanho da amostra foi de 384 indivíduos a serem investigados, entretanto, foram aplicados 404 questionários.

Com a intenção de buscar representatividade da população de Campo Grande, as entrevistas foram distribuídas, estrategicamente, próximas a pontos de vendas de carne de peixe localizados nas entradas das principais vias de acesso às sete regiões administrativas da cidade (Centro, Segredo, Prosa, Bandeira, Anhanduizinho, Lagoa, Ibirussu).

As informações coletadas foram tabuladas e tratados nos softwares Sphinx Léxica 5.0 e SPSS 13.0, com a aplicação de análises univariadas, bivariadas e multivariadas, tendo em vista os objetivos da pesquisa.

$\mathrm{Na}$ análise univariada foram observadas as frequências das variáveis para caracterizar o perfil do consumidor de carne de peixe. A análise bivariada tratou do cruzamento de informações sobre o consumo de carne de peixe com as variáveis sexo, idade, renda, escolaridade e tamanho da família, que definem uma segmentação do mercado, com o intuito de identificar os hábitos e preferências dos consumidores com relação à carne de peixe. Para verificar a significância dos cruzamentos de informações foi aplicado o teste de associação do Quiquadrado, com o cálculo do $\mathrm{p}_{\text {valor }}$.

Por último, com a finalidade de se descobrir a existência de ligação entre uma variável dependente e várias variáveis independentes foi realizada uma análise de correspondência múltipla. Com essa análise foi possível identificar se a 
explicação da variável dependente estaria relacionada a outros fatores, os quais estariam ocultos se analisados de forma isolada ou utilizando apenas a análise bivariada.

A técnica de análise de correspondência múltipla utilizada neste trabalho foi a de análise fatorial por meio do processo de rotação ortogonal varimax, o que viabiliza a interpretação dos dados de diversas variáveis simultaneamente. Seu algebrismo e geometria fazem com que essa análise pertença a uma família de técnicas de disposição gráfica que tem como objetivo achar um subespaço que melhor ajuste o conjunto de pontos no espaço euclidiano. Este ajuste é feito pelo método de quadrado mínimo ponderado, em que a distância euclidiana generalizada (ponderada) é utilizada em um sistema de massas pontuais (FREITAS; MASCAROLA, 2000; FREITAS; JANISSEK, 2000).

\section{Resultados e Discussão}

\subsection{Perfil dos consumidores}

A segmentação de mercado é o processo de separar os consumidores em cluster, de maneira que suas necessidades e desejos sejam genericamente atendidos, tenham características específicas, que sejam semelhantes para que pertençam ao mesmo grupo e diferentes dos demais grupos (ROCHA et $a l, 2013)$. Um tipo de segmentação muito utilizado pelas empresas e profissionais de marketing é a segmentação demográfica, que consiste em separar os consumidores baseados nas variáveis demográficas, pois esta informação conduz a uma identificação e qualificação do mercado alvo (KOTLER; KELLER, 2012).

Na realização da pesquisa de campo foram abordados $59 \%$ de indivíduos do sexo feminino e $41 \%$ do sexo masculino, indicando que as mulheres são as principais responsáveis pela compra de gêneros alimentícios da família. Neves (2005) afirma que a mulher é quem toma a decisão sobre os alimentos a serem consumidos na residência e toma a decisão sobre os pratos a serem consumidos durante a semana. Resultado semelhante também foi encontrado por Boone e Kurtz (2009), em que a mulher é a responsável pela aquisição dos alimentos que a família consome.

Kotler e Keller (2012) explicam que, tradicionalmente, as esposas são as agentes de compras da família, principalmente, para alimentos e roupas, porém estes valores sociais estão modificando e a mulher está compartilhando com os maridos as responsabilidades domésticas, como a compra de supermercado.

Quanto à faixa etária dos consumidores que vão às compras, $9 \%$ tinham menos de 20 anos, $6,35 \%$ entre 21 a 30 anos, $31 \%$ entre 31 a 40 anos, $16 \%$ entre 41 a 50 anos e $8 \%$ tinham mais de 50 anos. A variável idade é de suma importância para o direcionamento de estratégias de marketing, uma vez que os desejos e as necessidades mudam com a idade (KOTLER; KELLER, 2012).

O estado civil pode ser um bom indicativo de potencial de consumo, tendo sido constatado que $52 \%$ dos entrevistados eram casados, $40 \%$ solteiros, $7 \%$ divorciados ou separados e apenas $1 \%$ eram viúvos. Dos casados entrevistados, 33\% alegavam morar com mais três pessoas, dos solteiros $28,7 \%$ moravam com mais duas pessoas.

Identificou-se que 93,3\% dos consumidores entrevistados consomem carne de peixe. Desses consumidores de carne de peixe, 3\% declararam consumir a carne de peixe apenas na quaresma, 29\% consumiam eventualmente, 17\% uma vez por mês, $20 \%$ uma vez a cada quinze dias, $17 \%$ uma vez por semana e $8 \%$ mais de uma vez por semana.

Com relação à renda, a maioria dos consumidores entrevistados $40 \%$ alegavam possuir renda entre R $\$ 1.000,00$ e R\$ $2.500,00,21 \%$ entre $R \$ 2.500,00$ e $\mathrm{R} \$ 4.000,00,11 \%$ de $\mathrm{R} \$ 4.001,00$ a $\mathrm{R} \$ 5.500,00$ e $17 \%$ acima de $\mathrm{R} \$ 5.000,00$. Portanto, a renda não é determinante no consumo da carne de peixe, visto que a distribuição dos consumidores entre as classes de rendas foi bastante homogênea. Segundo Kotler e Keller (2012), a segmentação por renda é uma prática muito utilizada pelas empresas e profissionais de marketing para direcionar ações para determinado tipo de produto.

Quanto ao número de pessoas que residiam na casa, incluindo o entrevistado, identificou-se que 5,4\% residiam sozinhas, $23,3 \%$ duas pessoas, $30,9 \%$ três pessoas, $21,8 \%$ quatro pessoas, $13,4 \%$ cinco pessoas e, 5,2\% afirmaram residir mais de cinco pessoas. Com relação ao número de crianças que residem no domicílio, $55,2 \%$ afirmaram não ter nenhuma criança e $28,5 \%$ apenas uma.

Quanto à frequência semanal de compras de alimentos, $31 \%$ dos entrevistados iam às compras ao menos uma vez por semana e $26 \%$ mais de uma vez por semana, para evidenciar as respostas mais expressivas, este resultado é similar ao estudo realizado por Lopes, Oliveira e Ramos (2016), no qual eles identificam que a preferência da população brasileira em geral, é pela carne de bovina, diferenciando apenas da região Norte, destacando o consumo pela carne de peixe em 70,7\%.

Com intuito de identificar a preferência dos consumidores quanto ao tipo de carne, foi solicitado aos entrevistados que elegessem três tipos de carne em ordem de preferência. A carne bovina ficou em primeiro lugar com $33 \%$, em segundo lugar a carne de frango com $25 \%$ e, em terceiro, a carne de peixe com $24 \%$. A carne suína ficou em quarto lugar na ordem de preferência, com $15 \%$, a ovina com $2 \%$ e $1 \%$ outros tipos de carne.

A preferência pela carne bovina está associada com questões históricas e culturais associadas à pecuária bovina de corte no Estado de Mato Grosso do Sul (RIBEIRO; CORÇÃO, 2013). Segundo Silva et al. (2007), com relação ao consumo de carne de frango, possivelmente, por se tratar de uma carne com preço mais baixo, como também, por ser uma carne saudável, com baixo teor de gordura e de fácil preparo.

Com relação aos consumidores de peixe, questionados sobre os motivos pelos quais consomem esse tipo de carne, $53 \%$ dos consumidores responderam que era pelo benefício à 
saúde, relacionada à qualidade nutricional dessa carne, 20\% alegavam que era pelo sabor, $13 \%$ diziam que era para variar o cardápio familiar, $5 \%$ era por hábito de consumo e por ser uma carne de fácil digestão e, $9 \%$ por outros motivos.

Nesta pesquisa ficou claro que os consumidores tinham a percepção de que a carne de peixe proporcionava grandes benefícios à saúde. Segundo Pescador (2006), o consumo de peixe pelo menos duas vezes por semana previne doenças cardiovasculares e coronarianas. Estas doenças são causadas pela combinação de diversos fatores de riscos, e o ômega 3, associado às atividades cardioprotetoras dos ácidos graxos, combatem diretamente a ação destes riscos. Quanto ao sabor da carne de peixe representa uma característica importante, o que deveria ser mais explorado de forma comercial visando aumentar o consumo desse tipo de carne.

De acordo com Instituto Brasileiro de Geografia e Estatística (IBGE, 2003), a alimentação fora de casa se apresenta como um mercado com alto potencial econômico, pois representa $25 \%$ do gasto familiar com alimentação no Brasil. Comer fora de casa deixou de ser uma prática reservada para ocasiões especiais e se tornou uma necessidade imposta pelos ritmos da vida atual (SCHUBERT et al., 2017).

Corroborando com os autores sobre a alimentação fora de casa, Campo Grande também sente essa mudança de hábitos da população. Além do mais, esta cidade sofre uma forte influência da culinária japonesa, basicamente, composta de peixes e frutos do mar. Nos últimos anos se observou um grande aumento de estabelecimentos que comercializam este tipo de alimento na cidade, o que propicia um aumento do consumo da carne de peixe.

As espécies preferidas pelos consumidores de Campo Grande eram o Pacu (22\%), o Pintado (21\%), o Dourado (11\%) e a Sardinha (11\%). Coincidentemente, eram essas as espécies preferidas pela população da cidade quando da pesquisa realizada por Michels e Prochmann (2003).

Nessa pesquisa foram identificados os locais em que os consumidores de carne de peixe preferem comprar esse produto. A preferência de $56 \%$ dos consumidores entrevistados era a de comprar peixes nos supermercados, $22 \%$ nas peixarias, $10 \%$ no Mercado Municipal de Campo Grande, $6 \%$ preferiam conciliar a compra com o lazer e buscar os pesque e pagues ou pesqueiros e, $4 \%$ preferiam outros locais de distribuição.

Buscou-se verificar, também, a preferência dos consumidores quanto à embalagem da carne de peixe. Os dados mostraram que a maioria, $35 \%$ dos consumidores de Campo Grande não tinham preferência por embalagens, 32\% preferiam em bandejas, $12 \%$ preferiam de outras formas não especificadas, pressupondo-se que para, pelo menos $44 \%$ dos consumidores, a embalagem pode ser um fator determinante na compra.

\subsection{Comportamento dos consumidores de carne de peixe}

Como já mencionado de que é a mulher que toma a decisão sobre os alimentos a serem consumidos na residência e toma a decisão sobre os pratos a serem consumidos durante a semana, foi verificado se esse fato poderia ser um fator determinante de consumo. Foram cruzados, então, a variável "sexo" com a variável "se consome carne de peixe", obtendose respostas muito semelhantes entre os dois sexos. Portanto, a dependência não foi significativa $(p=0,91)$. Assim, o sexo não tem influência sobre o consumo de carne de peixe.

A carne de peixe é muito apreciada pelo cidadão campograndense, em todas as faixas etárias, com destaque para pessoas na faixa etária acima de 40 anos, pois foram as que, em maior número, declararam consumir esse tipo de carne, em média 98,2\%, inclusive, aquelas pessoas acima de 60 anos foram unânimes em declarar que apreciam a carne de peixe, o que permite inferir que as pessoas com idades mais avançadas estão buscando alimentos mais saudáveis

Kotler e Keller (2012) afirmam que a variação do composto etário da população sinaliza que tipo de produtos e serviços terá maior demanda nos próximos anos, portanto identificar faixa etária dos consumidores pode ser um fator determinante na decisão de compra de determinados produtos.

Constatou-se que a escolaridade do indivíduo não influencia na condição de ser ou não consumidor de carne de peixe, pois ao cruzar essas duas informações, verificou-se que a dependência não foi significativa, $p=0,21$. Segundo Costa, Almeida e Oliveira (2009), quanto mais elevado é o grau de escolaridade do consumidor de carne de peixe, mais preocupação ele tem com a qualidade do pescado. Esse fato não foi constatado pela presente pesquisa, visto que em todos os níveis de escolaridade existia preocupação do indivíduo com a qualidade do pescado.

Já a renda familiar exerce papel decisivo no consumo de carne de peixe, pois ao cruzar essas duas informações, a dependência entre essas foi muito significativa, $\operatorname{com} p=0$. No Quadro 1 se observa que a população da cidade de Campo Grande, em todas as faixas de rendas, consome carne de peixe, mas esse consumo é cada vez mais intenso com o aumento da renda familiar do indivíduo. As células em negrito, com frequências reais $98,6 \%$ e $12,5 \%$, indicam que as frequências reais encontradas são muito superiores às frequências teóricas, que são de $92,6 \%$ e $6,7 \%$, respectivamente. Já aquelas com realce na célula têm frequências reais $87,5 \%$ e $1,4 \%$, muito inferiores as mesmas frequências teóricas.

Quadro 1 - Análise da relação renda x consumidor de carne de peixe. Campo Grande, MS

\begin{tabular}{|l|c|c|c|}
\hline \multicolumn{1}{|c|}{ Renda Familiar } & Sim & Não & Total \\
\hline Abaixo de R\$ 1.000,00 & $87,50 \%$ & $12,50 \%$ & $100 \%$ \\
\hline Entre R\$ 1.001,00 a R\$ 2.500,00 & $91,00 \%$ & $9,00 \%$ & $100 \%$ \\
\hline Entre R\$ 2.501,00 a R\$ 4.000,00 & $94,10 \%$ & $5,90 \%$ & $100 \%$ \\
\hline Entre R\$ 4.001,00 a R\$ 5.500,00 & $95,60 \%$ & $4,40 \%$ & $100 \%$ \\
\hline Acima de R\$ 5.500,00 & $98,60 \%$ & $1,40 \%$ & $100 \%$ \\
\hline Total & $92,60 \%$ & $6,70 \%$ & $100 \%$ \\
\hline$p=0$.
\end{tabular}

Fonte: Dados da pesquisa.

O surgimento de famílias com duas rendas, do homem 
e da mulher, fez mudar o comportamento de consumo, pois, evidentemente, aumentou a renda familiar, como também mudou, consideravelmente, a maneira como a família divide as responsabilidades financeiras. As mulheres casadas com filhos trabalham fora, por sua vez, seus maridos ajudam nas obrigações domésticas (SCHIFFMAN; KANUK, 1997; BOONE; KURTZ, 2009). Em contrapartida, Samara e Morsch (2005) afirmam que a renda, por si só, não é um indicador de posição social, nem mesmo de capacidade de gasto, porém serve como indício das preferências e do estilo de vida do consumidor.

Como já analisado anteriormente, 31\% das famílias eram compostas de três pessoas e $23,3 \%$ com apenas duas pessoas, identificando que os núcleos familiares estão cada vez menores, consequentemente, o consumo das famílias são menores. $\mathrm{Na}$ verificação da dependência entre "número de pessoas da família" com "consumo ou não de carne de peixe", o resultado foi pouco significativo, $p=0,10$, indicando que o número de pessoas na família é um fator com pouca influência na decisão de comprar carne de peixe na cidade de Campo Grande.

Segundo Samara e Morsch (2005), a família é um dos grupos sociais mais influentes sobre o comportamento dos consumidores, pois os membros são diretamente ligados por laços sanguíneos, afetivos, de apoio e cuidado mútuo. A definição dos critérios a serem usados na decisão de consumo pode ficar a cargo de uma pessoa ou pela eleição dos membros.

No perfil dos consumidores se identificou que as pessoas do sexo feminino formam o maior grupo que é o responsável pelas compras dos alimentos das famílias, em torno de 59\%. Com isso, buscou-se realizar o cruzamento das variáveis "frequência de consumo" com "sexo", com o intuito de se verificar qual a relação existente entre ambas perante os entrevistados que consomem a carne de peixe (Quadro 2).

Quadro 2 - Resultados do cruzamento das variáveis "frequência de consumo" versus "sexo". Campo Grande, MS

\begin{tabular}{|l|c|c|c|}
\hline \multirow{2}{*}{ Frequência de Consumo } & \multicolumn{2}{|c|}{ Sexo } & \multirow{2}{*}{ Total } \\
\cline { 2 - 3 } & Masculino & Feminino & \\
\hline Mais de 1 vez por semana & $30,00 \%$ & $70,00 \%$ & $100 \%$ \\
\hline 1 vez por semana & $46,90 \%$ & $53,10 \%$ & $100 \%$ \\
\hline 1 vez a cada 15 dias & $46,10 \%$ & $53,90 \%$ & $100 \%$ \\
\hline 1 vezes por mês & $38,10 \%$ & $61,90 \%$ & $100 \%$ \\
\hline Eventualmente & $37,70 \%$ & $61,40 \%$ & $100 \%$ \\
\hline Apenas na época da quaresma & $33,30 \%$ & $66,70 \%$ & $100 \%$ \\
\hline Raramente & $48,80 \%$ & $51,20 \%$ & $100 \%$ \\
\hline Total & $\mathbf{4 1 , 3 0 \%}$ & $\mathbf{5 8 , 4 0 \%}$ & $\mathbf{1 0 0} \%$ \\
\hline
\end{tabular}

$p=0,41$.

Fonte: Dados da pesquisa.

No teste do Qui-quadrado se observou que a dependência não foi significativa $p=0,41$, indicando que o sexo não é um fator determinante na frequência do consumo da carne de peixe na cidade de Campo Grande.

O Quadro 3 apresenta o cruzamento das variáveis "frequência de consumo" com a "renda do consumidor", em que foi identificado que a relação é muito significativa $\mathrm{p}=0,002$, indicando que a renda dos consumidores é fator determinante na frequência do consumo de carne de peixe na cidade de Campo Grande. Observa-se que tanto as células em negrito, quanto aquelas em cinza claro, identificam os pontos significativos nesse cruzamento, em que, naquelas em negrito, as frequências reais são significativamente maiores do que as frequências teóricas e, aquelas com realce na célula, as frequências reais são menores do que as frequências teóricas. As frequências teóricas estão apresentadas na última linha do Quadro 3.

Quadro 3 - Análise da relação frequência de consumo x renda familiar. Campo Grande, MS

\begin{tabular}{|c|c|c|c|c|c|c|}
\hline \multirow[b]{2}{*}{ Frequência de Consumo } & \multicolumn{6}{|c|}{ Renda Familiar } \\
\hline & $\begin{array}{c}\text { Abaixo } \\
\text { R\$1.000 }\end{array}$ & $\begin{array}{c}\text { Entre } \mathbf{R} \$ 1.000 \\
\text { a } \mathbf{R} \mathbf{2 . 5 0 0}\end{array}$ & $\begin{array}{c}\text { Entre R\$2.500 a } \\
R \$ 4.000\end{array}$ & $\begin{array}{c}\text { Entre R\$4.000 a } \\
\text { R\$5.500 }\end{array}$ & $\begin{array}{c}\text { Acima de } \\
\text { R\$5.500 }\end{array}$ & Total \\
\hline Mais de $1 \mathrm{vez} /$ semana & $13,3 \%$ & $40,0 \%$ & $23,3 \%$ & $6,7 \%$ & $16,7 \%$ & $100 \%$ \\
\hline $1 \mathrm{vez} / \mathrm{semana}$ & $4,7 \%$ & $23,4 \%$ & $26,6 \%$ & $9,4 \%$ & $34,4 \%$ & $100 \%$ \\
\hline $1 \mathrm{vez}$ a cada 15 dias & $2,6 \%$ & $35,5 \%$ & $19,7 \%$ & $18,4 \%$ & $22,4 \%$ & $100 \%$ \\
\hline 1 vez por mês & $12,7 \%$ & $44,4 \%$ & $15,9 \%$ & $11,1 \%$ & $15,9 \%$ & $100 \%$ \\
\hline Eventualmente & $8,8 \%$ & $47,4 \%$ & $21,1 \%$ & $11,4 \%$ & $11,4 \%$ & $100 \%$ \\
\hline $\mathrm{Na}$ época da quaresma & $26,7 \%$ & $46,7 \%$ & $20,0 \%$ & $6,7 \%$ & $0,0 \%$ & $100 \%$ \\
\hline Raramente & $22,0 \%$ & $41,5 \%$ & $26,8 \%$ & $4,9 \%$ & $4,9 \%$ & $100 \%$ \\
\hline Total & $9,9 \%$ & $39,6 \%$ & $21,5 \%$ & $11,1 \%$ & $17,1 \%$ & $100 \%$ \\
\hline
\end{tabular}

$p=0$

Fonte: dados da pesquisa.

Com relação ao Quadro 3, aquelas famílias que têm rendimentos abaixo de $\mathrm{R} \$ 1.000,00$, em torno de $48,7 \%$, consomem carne de peixe apenas na quaresma ou muito raramente em outras datas, com dependência muito significativa $(p=0)$. As famílias com rendas acima de $\mathrm{R} \$$ $5.500,00$ em torno de 73,5\%, consomem carne de peixe frequentemente, de uma vez a cada quinze dias até mais de uma vez por semana.
No cruzamento das variáveis "frequência de consumo" com "motivos que o faz consumir", identificou-se que a relação é muito significativa, $p=0$. O motivo mais lembrado foi o benefício à saúde, com porcentagens bastante altas, em segundo lugar aparece o sabor como motivo na escolha da carne de peixe e, em terceiro lugar aparece a variação de cardápio como um motivo bastante citado. O Quadro 4 apresenta os resultados completos desse cruzamento. 
Quadro 4 - Resultados do cruzamento das variáveis "frequência de consumo" versus "Motivos para consumir peixe". Campo Grande, MS

\begin{tabular}{|l|c|c|c|c|c|c|c|c|}
\cline { 2 - 9 } \multicolumn{1}{c|}{$\begin{array}{c}\text { Frequência de } \\
\text { Consumo }\end{array}$} & $\begin{array}{c}\text { Benefício } \\
\text { Saúde }\end{array}$ & Hábito & Sabor & $\begin{array}{c}\text { Variar o } \\
\text { Cardápio }\end{array}$ & $\begin{array}{c}\text { Carne } \\
\text { branca }\end{array}$ & $\begin{array}{c}\text { Fácil } \\
\text { digestão }\end{array}$ & Outro & Total \\
\hline + de 1 vez / semana & $76.7 \%$ & $46.7 \%$ & $70.0 \%$ & $16.7 \%$ & $16.7 \%$ & $20.0 \%$ & $6.7 \%$ & $100 \%$ \\
\hline 1 vez / semana & $87.5 \%$ & $34.4 \%$ & $70.3 \%$ & $45.3 \%$ & $18.8 \%$ & $14.1 \%$ & $4.7 \%$ & $100 \%$ \\
\hline 1 vez / 15 dias & $73.7 \%$ & $22.4 \%$ & $64.5 \%$ & $60.5 \%$ & $7.9 \%$ & $22.4 \%$ & $9.2 \%$ & $100 \%$ \\
\hline 1 vez por mês & $76.2 \%$ & $25.4 \%$ & $74.6 \%$ & $58.7 \%$ & $17.5 \%$ & $17.5 \%$ & $9.5 \%$ & $100 \%$ \\
\hline Eventualmente & $73.7 \%$ & $17.5 \%$ & $57.9 \%$ & $61.4 \%$ & $14.9 \%$ & $13.2 \%$ & $11.4 \%$ & $100 \%$ \\
\hline Na quaresma & $80.0 \%$ & $20.0 \%$ & $60.0 \%$ & $40.0 \%$ & $20.0 \%$ & $20.0 \%$ & $6.7 \%$ & $100 \%$ \\
\hline Raramente & $56.1 \%$ & $17.1 \%$ & $51.2 \%$ & $34.1 \%$ & $9.8 \%$ & $9.8 \%$ & $\mathbf{5 1 . 2 \%}$ & $100 \%$ \\
\hline Total & $74.8 \%$ & $24.5 \%$ & $63.9 \%$ & $51.2 \%$ & $14.4 \%$ & $16.1 \%$ & $13.1 \%$ & $100 \%$ \\
\hline$p=0$ & & & & & & & \\
\hline
\end{tabular}

Fonte: dados da pesquisa.

\subsection{Fatores que Influenciam o Consumidor a Adquirir Carne de Peixe}

No Quadro 5 estão os resultados, em ordem decrescente, das médias aritméticas das questões em escala de Likert, com os respectivos desvios-padrão e coeficientes de variação, da percepção do consumidor sobre a importância de alguns fatores para a decisão de se comprar carne de peixe para a alimentação da família (sendo 1 = nada importante até 7 = muitíssimo importante).

Quadro 5 - Médias aritméticas, em ordem decrescente de importância, sobre a decisão do consumidor na compra ou não de carne de peixe para a alimentação da família, Campo Grande - MS

\begin{tabular}{|l|c|c|c|}
\hline \multicolumn{1}{|c|}{ Fator } & $\bar{x} *$ & $\mathbf{S}$ & $\mathbf{C V ( \% )}$ \\
\hline Aparência do produto & 6,61 & 1,20 & 18,2 \\
\hline $\begin{array}{l}\text { Local / atendimento / } \\
\text { disponibilidade do produto }\end{array}$ & 6,50 & 1,32 & 20,3 \\
\hline Sabor após o preparo & 6,45 & 1,31 & 20,3 \\
\hline Firmeza da carne do peixe & 6,29 & 1,37 & 21,8 \\
\hline Cheiro da carne do peixe & 6,19 & 1,64 & 26,5 \\
\hline Forma de exposição da carne & 6,12 & 1,55 & 25,3 \\
\hline Embalagem da carne & 5,66 & 1,83 & 32,3 \\
\hline Preço da carne & 5,63 & 1,76 & 31,3 \\
\hline Ausência de espinhos & 5,40 & 1,94 & 35,9 \\
\hline Média Geral & $\mathbf{6 , 0 9}$ & & \\
\hline
\end{tabular}

*1 = nada importante até 7 = muitíssimo importante.

Fonte: Dados da pesquisa.

$\mathrm{Na}$ análise dos resultados apresentados na Tabela 5 foi possível verificar que as médias aritméticas variaram de 5,40 a 6,61, com média geral igual a 6,09 , mais próxima do valor 6,00 cujo significado era que existia uma concordância que todos os fatores apresentados são importantes na decisão do consumidor em adquirir carne de peixe para a alimentação da família. A maior média aritmética desses fatores foi 6,61 , fator esse que trata da importância da aparência do produto na decisão de se adquirir carne peixe para a alimentação da família. Como esta média está mais próxima de 7,00, isso indica que o consumidor julga muito importante esse fator, isto é, a aparência do pescado na decisão da compra de carne de peixe para a sua alimentação e da família.

Ainda, na análise das respostas que estão explicitadas no Quadro 5, se percebe que a menor média foi 5,40. Essa questão tratava da decisão do consumidor de comprar carne de peixe, desde que a mesma não apresente espinhas, muito perigoso, principalmente, para crianças e idosos, podendo causar algum acidente com graves consequências. Como está mais próxima de 5,00, indica que na percepção do consumidor, ele acha importante a ausência de espinhas, na decisão de se comprar o produto para o consumo da família.

Um fator levado em consideração pelo consumidor na hora da compra foi o local de compra, o atendimento recebido e a disponibilidade em quantidade e espécie, atingindo média de 6,50, podendo ser arredondado para 7,00, indicando que esse fator é muito importante na decisão de se comprar carne de peixe.

Desse modo, o empresário deve ficar atento, pois, quanto ao atendimento, o número de locais de compra de carne de peixe e a disponibilidade de variedades de carne de peixe nesses locais, se melhorados, podem levar a um melhor consumo de carne de peixe em Campo Grande. Essas informações estão de acordo com o encontrado por Pineyrua et al. (2006), que afirmam que "o varejo de pescado da cidade de Campo Grande ainda tem grandes possibilidades de melhorar o oferecimento de pescado".

Os coeficientes de variação desse bloco de questões variam de $18,2 \%$ a $35,9 \%$, indicando de média a alta dispersão das médias dos fatores desse bloco de questões. Como o menor coeficiente de variação foi $18,2 \%$, o que indica uma média de dispersão das respostas, deixou transparecer que, realmente, a aparência é o primeiro item que o consumidor analisa para a decisão da compra da carne de peixe. Como o maior coeficiente de variação foi de $35,9 \%$, que corresponde à ausência de espinha como fator que influencia na compra, indicou uma alta dispersão das respostas. Conclui-se, assim, que a ausência de espinhas na carne de peixe pode ser importante para alguns consumidores, mas não importante para outros. É possível inferir que vai depender do preparo que o consumidor vai fazer da carne, que pode diminuir ou não o perigo das espinhas. 
Outros fatores como sabor, firmeza da carne, cheiro e formas de exposição do produto, com médias acima de 6,00, também foram fatores que variaram de importantes a muito importantes na decisão do consumidor em adquirir carne de peixe nas lojas especializadas.

\subsection{Segmentação de Mercado de Carne de Peixe em Campo Grande}

Ao cruzar, simultaneamente, as variáveis independentes "número de pessoas na família", "grau de escolaridade do responsável da família", "renda familiar", e a variável dependente "frequência de consumo de carne de peixe", foi possível observar a formação de dois grupos bem caracterizados, formados pelas proximidades entre os pontos no gráfico (Figura 1).

Figura 1 - Gráfico fatorial da variável dependente "frequência de consumo de carne de peixe" e as variáveis independentes "número de pessoas na família", "grau de escolaridade do cabeça da família" e "renda familiar"

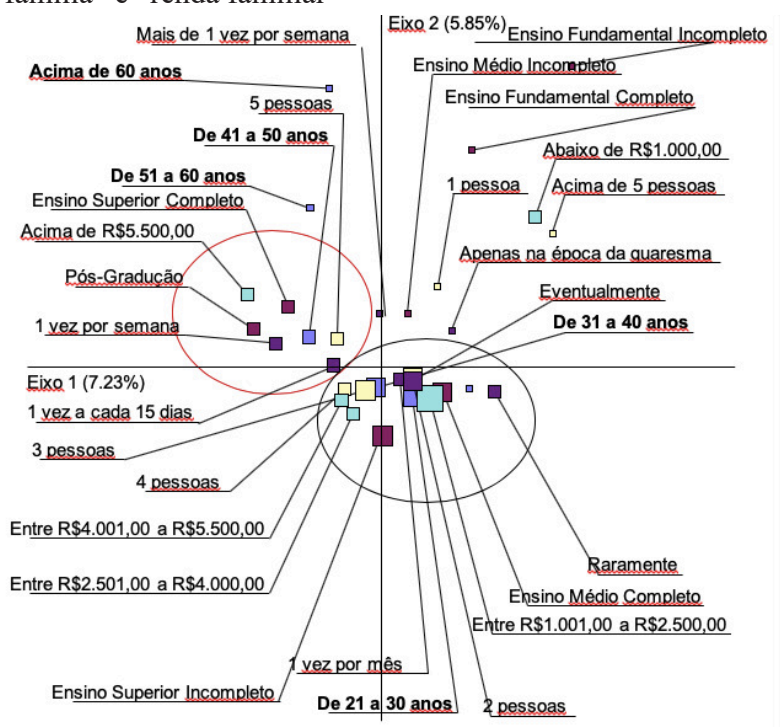

Fonte: Dados da pesquisa.

O primeiro agrupamento (círculo de contorno vermelho) é constituído de famílias constituídas de 5 membros, com renda familiar acima de $\mathrm{R} \$ 5.500,00$ e faixa etária variando de 41 a 60 anos. São famílias com grau de instrução elevado, sendo que, pelo menos o responsável da família, tem Ensino Superior completo ou mesmo Pós-graduação. O consumo de peixe nesse agrupamento de famílias é bastante elevado, consumindo esse produto pelo menos uma vez por semana e ou uma vez a cada quinze dias (Figura 1).

Para auxiliar a comercialização da carne de peixe, no Brasil faltam ações de marketing que informem aos consumidores as importâncias nutricionais que possuem a carne de peixe e os benefícios que o seu consumo traz à saúde. A partir do momento em que forem divulgadas, os consumidores poderão aumentar seu interesse pelo produto, o que pode levar a um incremento nas vendas de carne de peixe no País, além de uma melhoria na satisfação da população em relação à carne de peixe em sua forma processada.
Como sugestão, baseado nestes resultados, se destaca a necessidade de uma compreensão mais aprofundada na análise da disposição do consumidor em aumentar a frequência do consumo Nesse sentido, um estudo qualitativo, com entrevista em profundidade individual ou em grupos (focus group), pode auxiliar em uma melhor compreensão dos desejos e intenções dos consumidores.

\section{Conclusão}

Constatou-se nesta pesquisa que, na maioria das famílias campo-grandenses, os membros responsáveis pela compra de alimentação, bem como a decisão dos produtos a serem consumidos em casa, eram do sexo feminino, em torno de $59 \%$. Como a grande maioria dos consumidores da cidade, em todas as faixas etárias e de renda, tem grande preferência pela carne de peixe, independente de sexo, esse produto se faz presente, frequentemente, no cardápio de alimentação das famílias. A carne de peixe está em terceiro lugar no ranking da preferência de consumo das famílias, perdendo apenas para a carne bovina e de aves.

Entre os motivos que levaram os indivíduos a consumirem de carne de peixe estão o benefício à saúde relacionada à qualidade nutricional da carne de peixe. Os estabelecimentos de compra destes produtos preferidos pelos consumidores campo-grandenses são os supermercados, em função da praticidade, facilidade, qualidade dos produtos e por se concentrar a compra da família em um único local.

As espécies preferidas pelos consumidores da cidade de Campo Grande são Pacu, Pintado, Dourado e, Sardinha. Ficou evidenciado, ainda, que as embalagens podem ser um diferencial na preferência do consumidor em adquirir carne de peixe.

Particularmente, no setor gerencial, esta pesquisa traz contribuições no sentido de explorar melhor um mercado em potencial, que necessita do auxílio de profissionais de marketing no estabelecimento de estratégias condizentes para o aumento da oferta de carne de peixe com redução do preço, pesquisar novas embalagens, melhorar a conservação e a aparência do pescado, pois esse segmento de mercado tem um grande potencial econômico na cidade de Campo Grande.

\section{Referências}

BOONE, E.B.; KURTZ, D.L. Marketing contemporâneo. São Paulo: Cengage Learning, 2009.

BRASIL. Ministério da Pesca e Aquicultura. Boletim Estatístico da Pesca e Aquicultura Brasil, 2011, 2012. Disponível em: de http://www.icmbio.gov.br/cepsul/images/stories/biblioteca/ download/estatistica/est_2011_bol_bra.pdf

COSTA,A.D.; ALMEIDA, I.C.; OLIVEIRA, J.S. Mercado e perfil do consumidor de peixe no estado do Pará. In: CONGRESSO DA SOCIEDADE BRASILEIRA DE ECONOMIA E SOCIOLOGIA RURAL, Porto Alegre, RS, Brasil, 2009.

DA SILVA, A.P. et al. Perfil de consumo de peixe entre os universitários de Dourados, Mato Grosso do Sul. Arch. Vet. Scie., 
2016.

FAO. Organización de las Naciones Unidas para la alimentación y la agricultura. El Estado Mundial de La Pesca y La Acuicultura. 2016. Disponível em: http:/www.fao.org/3/a-i5555s.pdf

FAO. Organización de las Naciones Unidas para la alimentación y la agricultura. Estadísticas de pesca y acuicultura. 2011. Disponível em: http://www.fao.org/docrep/013/i1890t/i1890t.pdf

FONSECA, J.S.; MARTINS, G.A. Curso de estatística. São Paulo: Atlas, 2006.

FREITAS, H.; JANISSEK, R. Análise léxica e análise de conteúdo. Porto Alegre: Sagra Luzzatto, 2000.

FREITAS, H.; MASCAROLA, J. Análise de dados qualitativos e quantitativos: casos aplicados usando o Sphinx. Porto Alegre: Sagra Luzzatto, 2000.

IBGE. Instituto Brasileiro de Geografia e Estatística. Pesquisa de orçamentos familiar (2002-2003). Disponível em: http://www. ibge.org.br

KOTLER, P.; KELLER, K. L. Administração de marketing. São Paulo: Pearson Prentice Hall, 2012.

LOPES, I.; OLIVEIRA, R.G.; RAMOS, F.M. Perfil do consumo de peixes pela população brasileira. Rev. Biota Am., 2016. doi: http://dx.doi.org/10.18561/2179-5746/biotaamazonia. v6n2p62-65

MICHELS, I.; PROCHMANN, A.M. Piscicultura. Campo Grande: UFMS, 2003.

NEVES, M.L.C. Estratégias para desenvolvimento de agroindústrias de carne bovina apoiadas no conhecimento de valor para o consumidor. Campo Grande: Universidade para o
Desenvolvimento do Estado e da Região do Pantanal, 2005.

PESCADOR, R. Aspectos nutricionais dos lipídios no peixe: uma revisão de literatura. Brasília: Universidade de Brasília, 2006.

PINEYRUA, D.G.F. et al. Análise do pescado oferecido nos pontos de venda de Campo Grande, sob o ponto de vista dos clientes. In: SEMINÁRIO EM ADMINISTRAÇÃO FEA/USP, São Paulo, SP, Brasil, 2006.

RESENDE, E.K.; TAKAGI, J.S.; LOESCHNER, W. Diagnóstico das pisciculturas em Mato Grosso do Sul. Anais do Congresso brasileiro de produção de peixes nativos de água doce. In: ENCONTRO DE PISCICULTORES DE MATO GROSSO DO SUL, 1, Dourados, MS, Brasil, 2011.

RIBEIRO, C.S.G.; CORÇÃO, M. O consumo de carne no Brasil: entre valores socioculturais e nutricionais. Demetra, 2013. doi: http://dx.doi.org/10.12957/demetra.2013.6608

ROCHA, A.; FERREIRA, J.B.; SILVA, J. Administração de marketing: conceitos, estratégias, aplicações. Atlas, 2013.

SAMARA, B.S.; MORSCH, M. A. Comportamento do consumidor: conceitos e casos. São Paulo: Pearson Prentice Hall, 2005.

SCHIFFMAN, G.L.; KANUK, L. L. Comportamento do consumidor. Rio de Janeiro: LTC, 1997.

SCHUBERT, M.; SCHNEIDER, S.; MÉNDEZ, C.D. O “comer fora de casa" no Brasil, Reino Unido e na Espanha: uma revisão das bases de dados estatísticos oficiais e perspectivas para comparação. Estud. Soc. Agricul., v.25, n.2, p.276-304, 2017.

SILVA, L.M. et al. Perfil dos consumidores de carne de frango: um estudo de caso na cidade de Campo Grande, Estado do Mato Grosso do Sul. Rev. Inform. Econ., 2007. 